\title{
DESEMPENHO RODOVIÁRIO LABORATORIAL DO RESÍDUO DE MINERAÇÃO DE MANGANÊS DE LICÍNIO DE ALMEIDA - BA QUANDO MISTURADO COM A BRITA 1.
}

\author{
LABORATORY ROAD PERFORMANCE OF LICÍNIO DE ALMEIDA - BA MANGANESE MINING \\ WASTE, WHEN MIXED WITH BRITA 1
}

\author{
Glauber Miranda de Carvalhoa, Hélio Marcos Fernandes Vianab, Rubem Xerxes Trindade \\ Rodrigues $^{a}$, João Paulo Freire Rochaa, Gilson Rodrigues Junior a \\ ${ }^{a}$ Engenheiro civil autônomo, ${ }^{b}$ UniFTC (Vitória da Conquista, Bahia)
}

glaubermirandadecarvalho@gmail.com, viana.hmf@gmail.com, rubemxr@hotmail.com, sucesso@live.com, gilsoneng21@gmail.com

Submissão: 17 de agosto de 2020 Aceitação: 24 de janeiro de 2021

\section{Resumo}

O presente trabalho avaliou o comportamento do CBR, na energia intermediária de Proctor, quando são adicionadas porcentagens de $30 \%, 50 \%$ e $75 \%$ de brita 1 , em massa, ao rejeito de manganês que foi coletado na região do município de Licínio de Almeida. O objetivo foi encontrar uma mistura que atendesse satisfatoriamente aos requisitos do Departamento Nacional de Infraestrutura de Transportes (DNIT) estabelecidos em 2006 para construção de base de pavimentos rodoviários. Os ensaios laboratoriais realizados na energia intermediária de Proctor verificaram a eficiência de cada uma das misturas a partir dos valores de CBR e de sua expansão observados. Com base nos modelos estatísticos desenvolvidos, este trabalho constatou que uma mistura de rejeito de manganês-brita 1, com apenas 39,5\% de teor de brita 1 , em massa, atende às referidas exigências. A conclusão do trabalho destaca que a adição de um baixo teor de brita 1, em massa, ao rejeito de manganês torna real a possibilidade de obter dois benefícios: combater um problema ambiental e viabilizar de forma altamente qualitativa a construção da base, que é uma das mais importantes camadas do pavimento rodoviário.

Palavras-chave: Pavimento; Rejeitos; Manganês; Meio Ambiente

\section{Abstract}

This work aimed to use statistical modeling based on mixtures of materials, type of manganese tailingscrushed stone 1 to find a mixture that satisfactorily met the requirements of the DNIT (National Department of Transport Infrastructure) for the construction of a road pavement base. The crushed stone composed the studied mixtures in the contents of $30 \%, 50 \%$ and $75 \%$ by mass. Manganese tailings were classified as siltysand soil (A-4 from TRB, SM from USCS and NA from MCT); Thus, the CBR behavior was evaluated that takes basis on the efficiency of each of the mixture for the intermediate energy of Proctor. Furthermore, based on developed statistical models, it was found that a mixture of manganese-crushed stone 1, with only $39.5 \%$ of gravel content, by mass, it was possible to meet the requirements of the DNIT (2006) for base construction of road pavements. Finally, with the addition of a low content of crushed stone 1, in mass, to the manganese tailings, the possibility of obtaining two benefits is real: to combat an environmental problem and to make possible the construction of the base, which is one of the most important road pavement layers.

Keywords: Pavement; Tailings; Manganese; Environment

\section{INTRODUÇÃO}

Localizado no sudoeste baiano a cerca de
740 quilômetros da capital Salvador, Licínio de Almeida é um município do interior da Bahia e, segundo o IBGE (2019), em 2018 a sua 
população foi estimada em, aproximadamente, 12.406 habitantes. Apresentando um solo rico em manganês, é um município onde, desde a década de 1960, uma empresa mineradora iniciou a atividade de extração nesse município.

De acordo com Medeiros (2015), a maior parte do consumo mundial de manganês ocorre na indústria siderúrgica, principalmente na produção de aço, que absorve cerca de $90 \%$ de toda produção do metal. Destaca-se que as ligas metálicas obtidas com o manganês tendem a apresentar maior resistência mecânica, dureza, rigidez e resistência ao desgaste. $O$ manganês também é utilizado na fabricação de pilhas, baterias e em mandíbulas de alta resistência para corte de trilhos, por exemplo.

A extração do minério de manganês é uma atividade que contribui de forma significativa para a economia do país, sendo responsável por grande parte da geração de empregos para a população. Em contrapartida, é gerada uma grande quantidade de rejeito na região da mineradora. Com base em Castro (2011), o descarte do rejeito de manganês feito de forma incorreta prejudica o meio ambiente, contribuindo para a contaminação de nascentes, rios e lagos. Ainda para o mesmo autor, os impactos ambientais provocados pela atividade podem ser reduzidos com a utilização do rejeito de manganês. Para isso, é preciso a aplicação de técnicas de execução fácil e de baixo custo econômico.

No setor da construção civil, o uso do rejeito de manganês vem sendo estudado na indústria cerâmica. Com adição de $10 \%$ do rejeito de manganês à massa cerâmica, seria possível alcançar aumentos de até $130 \%$ na resistência à flexão da cerâmica vermelha.

Em termos conceituais, 0 rejeito de manganês quando lançado no meio ambiente pode ser considerado como sendo um solo, pois um dos conceitos clássicos de solo é todo material que pode ser escavado sem técnicas especiais (por exemplo: sem a utilização de explosivos).

Quando um determinado solo se apresenta inapropriado para a construção de rodovias, é possível estabilizar tal solo com a adição de outros materiais. A estabilização consiste em uma mistura do solo inadequado com um estabilizante, de modo que tal mistura alcance o elevado padrão exigido para a sua utilização em pavimentação rodoviária conforme descrito na norma do DNIT (2006). Dentre os muitos estabilizantes para solos encontrados no mercado, destacam-se o cimento Portland, a cal, o Road Building Intenational (RBI) e a brita. Dados de laboratório obtidos por Mendonça, Bueno e Fontes (1998) mostram que, na mistura solo-cal, para um tempo de cura de 28 dias e para o teor de $6 \%$ de cal, em massa, o valor do California Bearing Ratio (CBR) resultante foi 8,2 vezes maior do que o valor do CBR inicial do solo natural não misturado com a cal. França (2003) estudou o comportamento de quatro tipos de solos da Microrregião de Viçosa - MG, constituídos de textura argilo-areno-siltosa. Nesse trabalho, foram realizados ensaios de CBR e de resistência à compressão não confinada com três teores do RBI Grade 81 (2\%, 4\% e 6\%) e três períodos de cura (1, 7 e 28 dias). Concluiu-se que o solo teve um aumento significativo de resistência.

Há muito tempo a estabilização do tipo solobrita vem sendo utilizada para o uso em pavimentação no Brasil. Segundo Nogami e Villibor (1995), a mistura solo-brita começou a ser usada na década de 1950 no estado de São Paulo, mas somente na década de 1980 a mistura passou a ser empregada em maior escala. Bezerra Neto (2004), em um trabalho com solos da região de Campo Grande - MS, registrou que um solo arenoso tipo A-2-4 e LA das classificações Transportation Research Board (TRB) e Miniatura Compactada Tropical (MCT), respectivamente, quando compactado na energia intermediária de Proctor apresentou um CBR de $81 \%$ e expansão de $0 \%$. Contudo, o mesmo solo arenoso quando misturado com brita 1 , na proporção de $50 \%$, em massa, e compactado na energia modificada de Proctor alcançou um CRB de $290 \%$ e expansão de $0 \%$. Portanto, a adição da brita 1 juntamente com a utilização do processo de compactação na energia modificada de Proctor resultou em uma elevação de 3,58 vezes no valor do CBR, que era de $81 \%$ inicialmente.

De acordo com Bernucci e colaboradores (2008), certas misturas de solo-brita com $50 \%$ de brita, em peso, alcançam valores de CBR da ordem de $80 \%$ quando submetidas à energia modificada de Proctor; e misturas com $70 \%$ de brita, em peso, e $30 \%$ de solo atingem muitas vezes CBR acima de 100\%. Além disso, quase 
não há a perda de capacidade de suporte após a sua imersão em água. Oliveira Júnior, Araújo e Ayres (2018) também estudaram um solo A-2-4 (TRB), que foi utilizado na duplicação da rodovia CE-040, para misturas de solo-brita. Nesse estudo, constataram que 0 solo natural apresentava um CBR de $72,1 \%$ e uma expansão de $0,028 \%$ quando compactados na energia modificada de Proctor. Observou-se também que, quando o solo natural foi misturado apenas com $30 \%$ de brita, em relação ao peso da amostra, o CBR da mistura solo-brita alcançou um valor igual a $182,9 \%$ e a sua expansão permaneceu baixa, igual a $0,026 \%$. Assim, a mistura com a brita possibilitou uma elevação considerável no valor do CBR, aproximadamente 2,53 vezes o valor do CBR do solo natural.

Nos trabalhos da área rodoviária, frequentemente quando o agregado utilizado na mistura se trata de rocha ou de pedra britada, segue-se a classificação granulométrica apresentada na norma DNER-ME 037 (DNER, 1997a). Assim, tem-se que a brita é classificada como sendo: brita 4, brita 3, brita 2, brita 1 e brita 0 . A brita 0 de acordo com o glossário do DNER (DNER, 1997b) também é denominada de brita fina ou pedrisco. Podem ser citados como exemplos os trabalhos de Bezerra Neto (2004), Bernucci e colaboradores (2008), Sachet e colaboradores (2009), Xerez Neto (2013) e Pinto e Pinto (2015).

Mediante o exposto, esta pesquisa tem como objetivo avaliar o comportamento do CBR, na energia intermediária de Proctor, quando são adicionadas porcentagens de $30 \%, 50 \%$ e $75 \%$ de brita 1 ao rejeito de manganês que foi coletado na região do município de Licínio de Almeida. Além disso, este trabalho aponta dois alvos distintos. Primeiro, combater o problema ambiental causado pelo descarte do rejeito de manganês no meio ambiente de forma inadequada, o que pode causar a contaminação de nascentes, rios e lagos; e segundo, com base no manual de pavimentação de 2006 elaborado pelo DNIT (DNIT, 2006) e através de previsões realizadas a partir modelos estatísticos, recomendar a utilização de uma mistura composta por rejeito de manganês e brita 1 para servir de base em pavimentos rodoviários.

\section{MATERIAIS E MÉTODOS}

Neste tópico, faz-se uma análise detalhada do rejeito de manganês de Licínio de Almeida BA do ponto de vista geotécnico. Descrevem-se também alguns aspectos relacionados à coleta do rejeito e informações acerca da brita 1 utilizada na mistura com o rejeito de manganês. No final, descrevem-se alguns procedimentos laboratoriais sobre a elaboração e a avaliação das misturas de rejeito de manganês e brita 1 . Destacam-se também algumas características das análises dos dados realizadas, de modo que se obtivesse a mistura satisfatória em termos de CBR e expansão, ou seja, aquela que estivesse de acordo com o padrão estabelecido pelo DNIT (2006) para construção de bases de pavimentos rodoviários.

\subsection{Coleta do rejeito}

Para a realização dos ensaios geotécnicos deste trabalho, retirou-se uma amostra do rejeito de manganês de massa igual a $180 \mathrm{~kg}$, conforme a norma NBR 9604 (ABNT, 1986b), de um dos locais de descarte de uma empresa que realizou a exploração do minério de manganês na cidade Licínio de Almeida - BA durante muitos anos. O local onde foi realizada a coleta da amostra apresenta as seguintes coordenadas geográficas: latitude $14^{\circ} 40^{\prime} 43,1^{\prime \prime} \mathrm{S}$ e longitude $42^{\circ} 30^{\prime} 53,8^{\prime \prime}$ W. A figura 1 ilustra a realização da coleta do rejeito em uma duna de rejeito de manganês que se localiza nas proximidades ao fundo do estádio municipal da cidade de Licínio de Almeida - BA. $\mathrm{Na}$ sequência, a amostra foi armazenada no Laboratório de Solos, submetida às preparações, segundo a norma NBR 6457 (ABNT, 1986a), e foram realizados ensaios para serem alcançados os objetivos desta pesquisa. A figura 2 destaca 0 rejeito de manganês sendo secado por um período de 4 dias para que se obtivesse a umidade higroscópica do material.

\subsection{Avaliação do rejeito de manganês}

O rejeito de mineração de manganês coletado em Licínio de Almeida - BA foi analisado no Laboratório de Geotecnia da Empresa Municipal de Urbanização de Vitória da Conquista (EMURC), no Laboratório de Geotecnia da Universidade Federal de Viçosa - MG (UFV) e no Laboratório do Instituto de Física de São Carlos SP (IFSC). A partir dos dados dos ensaios 
realizados, verificou-se que a amostra do rejeito do minério de manganês não apresentou Limite de Liquidez (LL) nem Limite de Plasticidade (LP). Portanto não existiu Índice de Plasticidade (IP) para o material. O valor obtido para a massa específica dos sólidos do rejeito foi $\rho s=3,331$ $\mathrm{g} / \mathrm{cm}^{3}$. A curva granulométrica do rejeito de manganês de Licínio de Almeida - BA é apresentada na figura 3 .

Em face dos resultados dos ensaios de classificação de solos obtidos nos laboratórios, o rejeito de manganês foi classificado como sendo um solo A-4 pela Transportation Research Board (TRB), que é a classe dos solos siltosos, com pequena quantidade de material grosso e pequena quantidade de argila. $O$ rejeito foi considerado um solo NA' (solo não laterítico arenoso) pela classificação Miniatura Compactada Tropical (MCT). E finalmente, o rejeito de manganês enquadrou-se como sendo um solo SM (sand-mo), ou areias siltosas, de acordo com a classificação Unifield Soil Classification System (USCS).

A figura 4 ilustra a fase de sedimentação do ensaio de granulometria, quando, em proveta, o rejeito de manganês estava misturado com uma solução de água destilada e hexametafosfato de sódio.

Os ensaios de compactação e de CBR na energia intermediária de Proctor com o rejeito de manganês original com ou sem misturas foram realizados com base nas normas DNER ME 49 (DNER, 1994) e NBR 9895/1987 (ABNT, 1987), respectivamente.

\section{Figura 1 - Escavação e coleta da amostra de rejeito de manganês em Licínio de Almeida - BA}

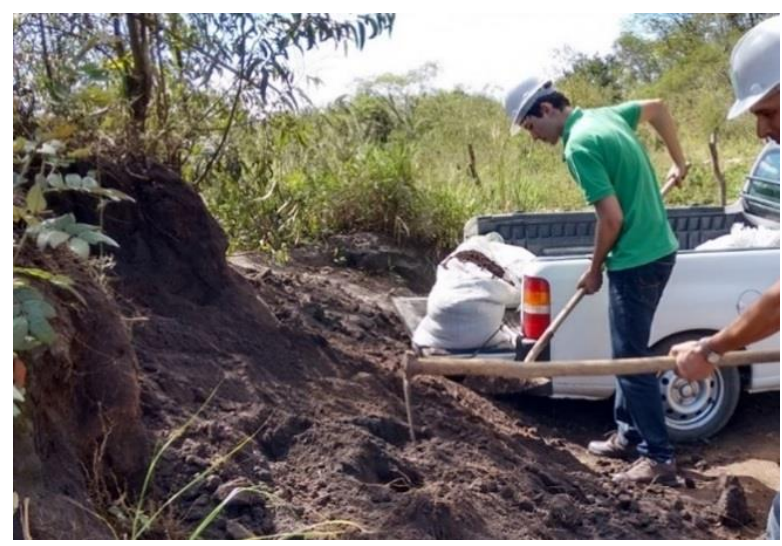

Fonte: Acervo dos autores (2015).

Figura 2 - Rejeito de manganês sendo secado por um período de 96 horas

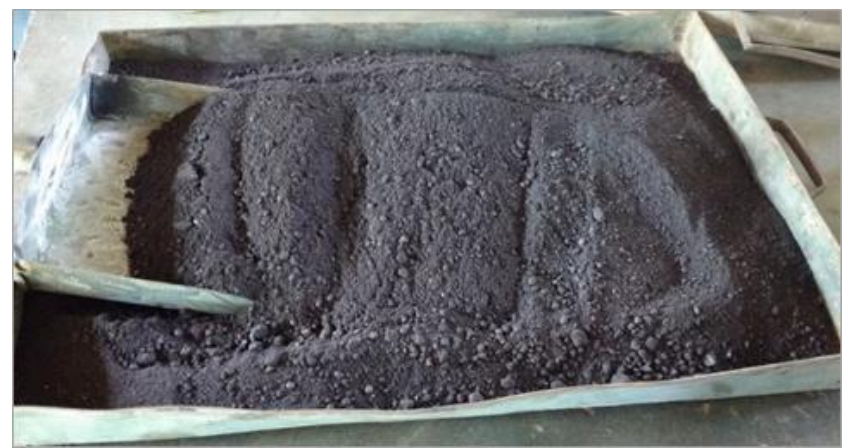

Fonte: Acervo dos autores (2015). 
Figura 3 - Curva granulométrica da amostra do rejeito de manganês

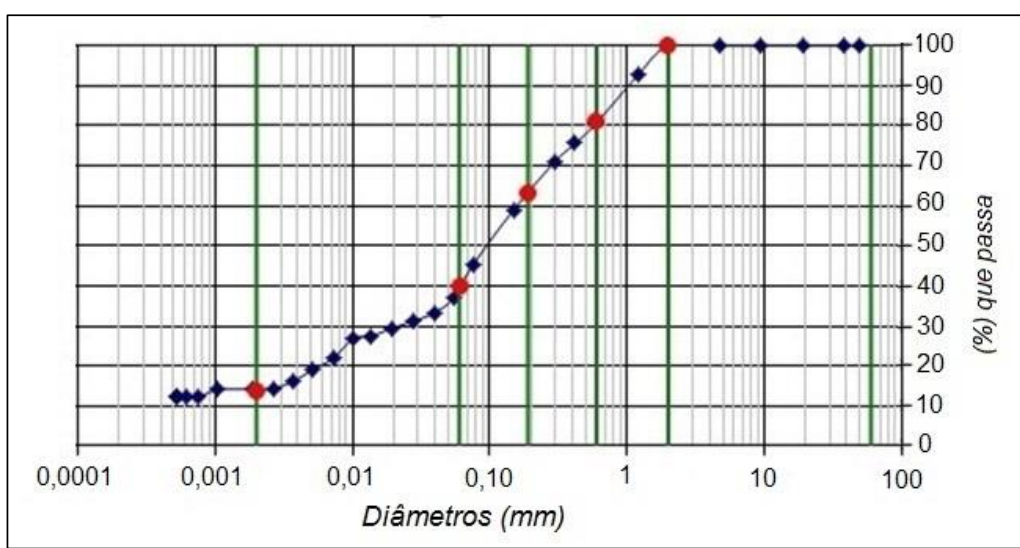

Fonte: Laboratório de Geotécnica da Universidade Federal de Viçosa (2015).

Figura 4 - Fase de sedimentação do ensaio de
granulometria com o rejeito de manganês

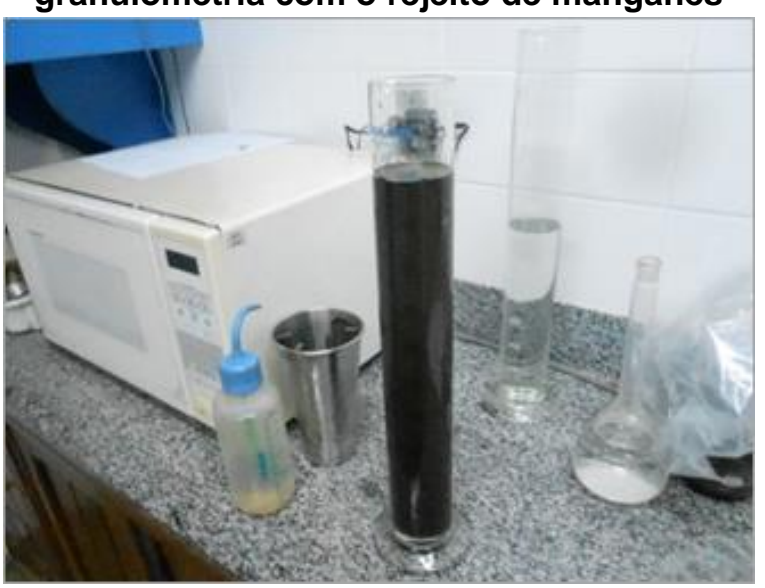

Fonte: Laboratório de Geotécnica da Universidade

Federal de Viçosa (2015).

As figuras 5 e 6 mostram esses resultados. $\mathrm{Na}$ figura 5 , observa-se que, para a energia intermediária de Proctor, o rejeito de manganês apresenta um teor de umidade ótimo de $26,8 \%$ e uma massa específica seca máxima de 1,720 $\mathrm{g} / \mathrm{cm}^{3}$. A figura 6 apresenta o resultado do ensaio CBR na energia intermediária de Proctor realizado com o rejeito de manganês. Foi obtido um valor máximo de CBR de $64 \%$ para um teor de umidade $26,8 \%$. Destaca-se que, após ter sido compactado na energia intermediária de Proctor em ensaio CBR e ter passado pela imersão padronizada de 96 horas, o rejeito de manganês sem misturas apresentou uma expansão máxima de $0,1 \%$.

A constituição mineralógica do rejeito de manganês foi avaliada a partir do ensaio de difração de raios $X$, com o difratômetro de raios $X$ do Instituto de Física de São Carlos (IFSC). Assim sendo, observou-se, no rejeito de manganês, a presença dos seguintes minerais: gismodina, muscovita, caulinita e quartzo. A figura 7 mostra o resultado do ensaio de difração de raios $\mathrm{X}$ realizado no rejeito de manganês.

\subsection{Avaliação da brita utilizada no trabalho}

Tendo sido a brita o material escolhido para estabilizar o rejeito de manganês de modo que fosse possível alcançar os valores elevados de CBR previstos pelo DNIT (2006) para construção de bases de pavimento, era necessário conhecer mais profundamente as suas características, e descrevê-las, para usá-la neste estudo. Para que fosse possível realizar os ensaios previstos, obteve-se uma quantidade expressiva de brita 1 
Revista Eletrônica de Gestão e Tecnologias Ambientais (GESTA)

oriunda de rocha do tipo gnaisse de uma pedreira. Na sua grande maioria, essa brita tinha diâmetros variando entre $9,5 \mathrm{~mm}$ e $19 \mathrm{~mm}$. Assim, de acordo com a classificação granulométrica da norma DNER ME 037 (DNER, 1997a), ela foi classificada como brita 1. E com base na norma DNER ME 81 (DNER, 1998), quando ensaiada, a brita 1 apresentou uma massa específica dos sólidos igual a $2,663 \mathrm{~g} / \mathrm{cm}^{3}$, para o peso específico padrão da água a $1 \mathrm{~g} / \mathrm{cm}^{3}$ a $4^{\circ} \mathrm{C}$.

Figura 5 - Curva de compactação, na energia intermediária de Proctor, do rejeito de manganês



Fonte: Laboratório da EMURC (2015).

Figura 6 - Resultado do ensaio CBR, na energia intermediária de Proctor, com o rejeito de manganês

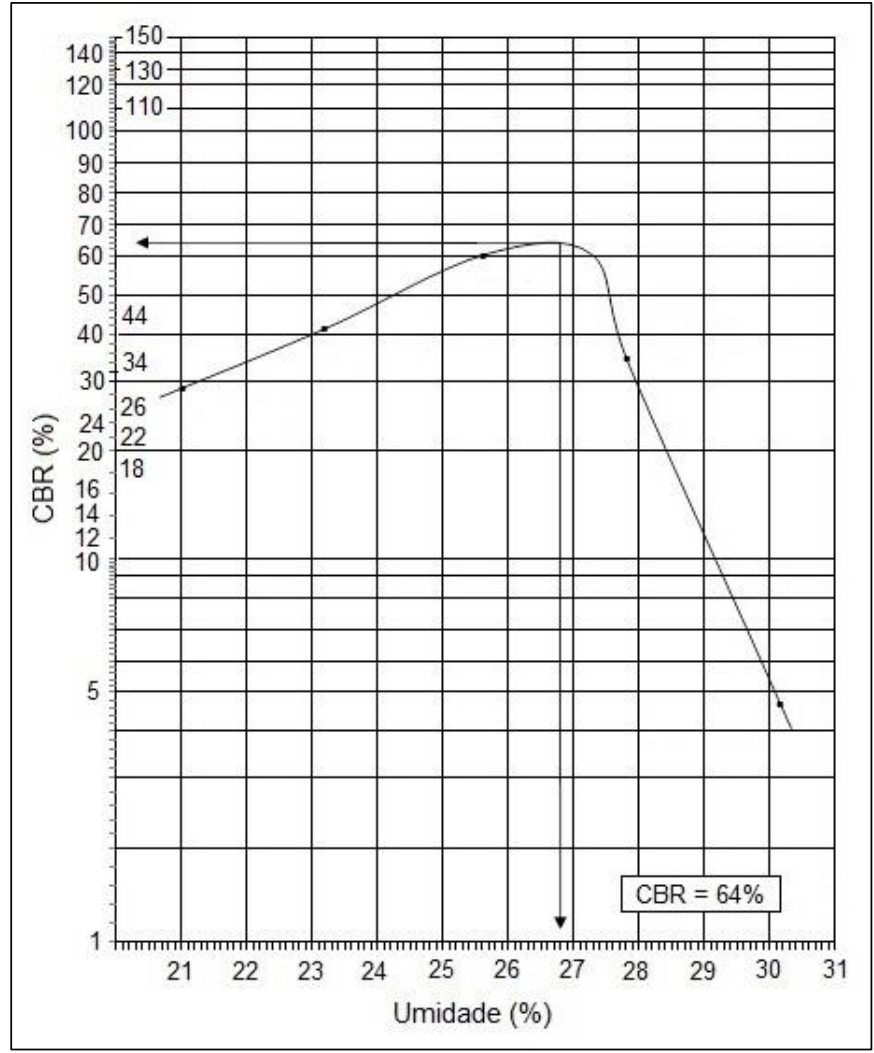

Fonte: Laboratório da EMURC (2015). 
Figura 7 - Difratograma do rejeito de manganês do município de Licínio de Almeida - BA

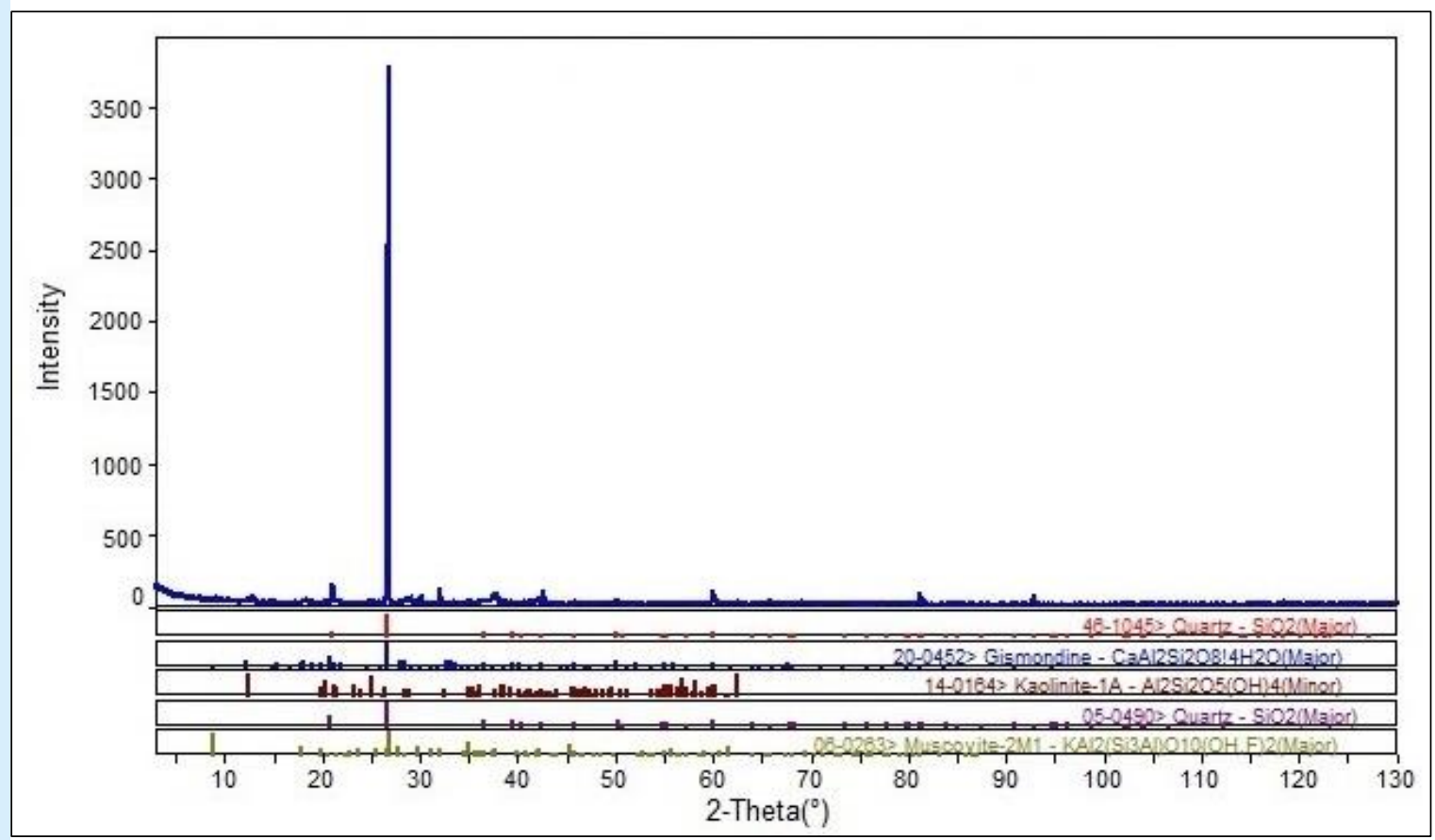

Fonte: Laboratório do IFSC (2016).

A figura 8 mostra o resultado do ensaio de análise granulométrica realizado com a brita 1 utilizada neste estudo. Pode-se observar também na figura 8 que a quantidade da brita $1 \mathrm{com}$ diâmetro de $9,5 \mathrm{~mm}$ retida na peneira foi, aproximadamente, igual a $99 \%$.

Figura 8 - Curva granulométrica da brita 1 utilizada para estabilizar o rejeito de manganês



Fonte: Laboratório da EMURC (2017).

Finalmente, a figura 9 ilustra, por meio de uma foto, a brita 1 da rocha do tipo gnaisse utilizada para estabilizar o rejeito de manganês.

2.4 Breve relato dos procedimentos de laboratório e das análises dos dados

Depois da avaliação laboratorial do rejeito de manganês sem adição de qualquer mistura estabilizante e de efetuada a sua classificação como sendo um solo, através dos diversos métodos geotécnicos, foram realizadas diferentes misturas da brita $1 \mathrm{com} 0$ referido rejeito. $\mathrm{Na}$ realização desse procedimento, foi estabelecida uma ordem de proporção dos dois materiais considerados com relação à massa total em cada 
mistura. Assim sendo, os teores de brita 1 adicionados às misturas foram de $30 \%, 50 \%$ e $75 \%$. Após a preparação das misturas, os ensaios de compactação de Proctor e CBR, ambos na energia intermediária, foram feitos.

Com a utilização de um programa estatístico, procedeu-se às diversas análises com base em modelos em que se considerou o material original, o rejeito de manganês sem misturas, e os materiais que se originaram das misturas do rejeito com a brita 1. Então, finalmente, foi possível prever, de forma precisa, um teor de brita 1 ideal para ser misturada ao rejeito de manganês e atender aos padrões de qualidade estabelecidos pelo DNIT (2006) para a construção de base de pavimentos rodoviários.

\section{Figura 9 - Brita 1 utilizada na mistura para estabilizar o rejeito de manganês}

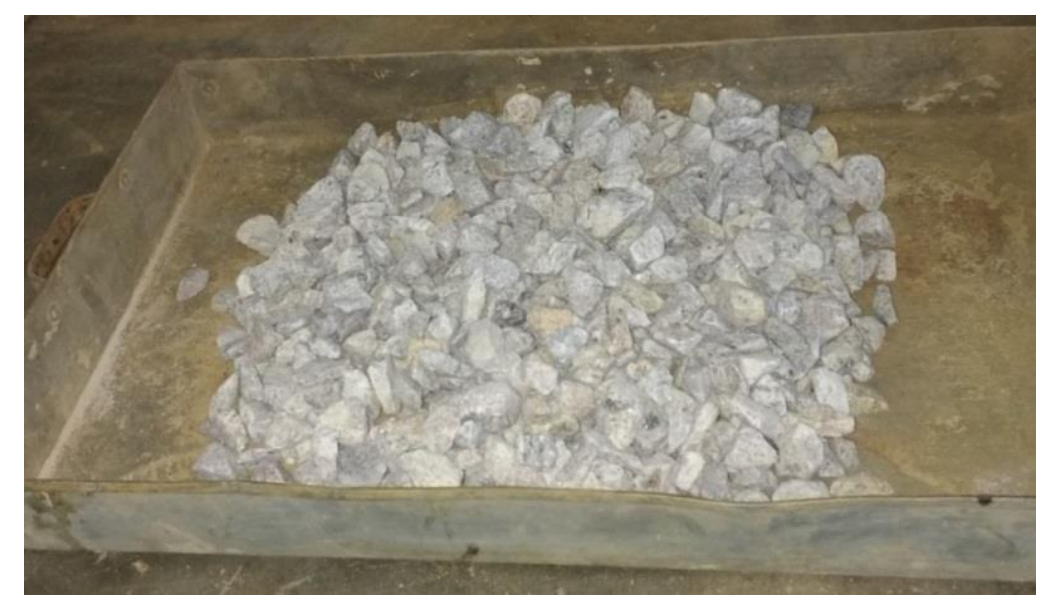

Fonte: Acervo dos autores (2017).

\section{ANÁLISE E DISCUSSÃO DOS RESULTADOS}

Neste tópico, são apresentados e discutidos os principais resultados deste trabalho. Assim, com base nos dados obtidos por meio dos ensaios laboratoriais, e levando em conta os gráficos dos modelos desenvolvidos a partir de quatro regressões estatísticas não lineares geradas a partir de um programa computacional, foi possível avaliar a qualidade das misturas de rejeito de manganês-brita 1 segundo as recomendações da norma do DNIT (2006).

A tabela 1 mostra os resultados dos ensaios de compactação e CBR na energia intermediária de Proctor realizados no laboratório da EMURC. Pode-se verificar que foram realizados 4 (quatro) ensaios de compactação sendo um ensaio com o rejeito de manganês sem mistura e 3 (três) ensaios realizados com a mistura rejeito de manganês-brita 1 , nas proporções $30 \%, 50 \%$ e $75 \%$ de brita 1 , em massa, na mistura. Observa-se ainda que o maior CBR foi obtido na mistura com o teor de $50 \%$ de brita 1. Na mistura com essa proporção também se obteve um teor de umidade ótimo de $2,20 \%$, menor do que aquele apresentado para o rejeito de manganês sem misturas.

\section{Tabela 1 - Resultados dos ensaios de compactação e CBR dos materiais na energia intermediária de Proctor}

\begin{tabular}{|c|c|c|c|c|}
\hline $\begin{array}{c}\text { Teor de brita 1 na } \\
\text { mistura (\%) }\end{array}$ & $\begin{array}{c}\text { Massa específica seca } \\
\text { máxima }\left(\mathbf{g} / \mathrm{cm}^{3}\right)\end{array}$ & $\begin{array}{c}\text { Teor de umidade } \\
\text { ótimo (\%) }\end{array}$ & CBR (\%) & $\begin{array}{c}\text { Expansão } \\
(\%)\end{array}$ \\
\hline 0 & 1,720 & 26,80 & 64 & 0,10 \\
\hline 30 & 1,930 & 25,00 & 76 & 0,10 \\
\hline 50 & 1,995 & 24,60 & 96 & 0,00 \\
\hline 75 & 2,078 & 23,60 & 90 & 0,00 \\
\hline
\end{tabular}

Fonte: Laboratório da EMURC (2017). 


\subsection{Comportamento do teor de umidade ótimo das misturas}

A figura 10 mostra a variação do teor de umidade ótimo das misturas do rejeito de manganês-brita 1 para os teores de brita, em massa, de $0 \%, 30 \%, 50 \%$ e $75 \%$, obtidos nos ensaios de compactação de Proctor na energia intermediária. Provavelmente, se o número de pontos fosse maior, o valor do $R^{2}$ (coeficiente de determinação) seria um pouco menor do que 1 . Além disso, verifica-se que, a partir do teor de brita de $30 \%$, à proporção que se aumenta o teor de brita (TB), a umidade ótima do solo diminui de forma quase linear até uma umidade de 23,6\%. Dessa forma, percebe-se que, para as misturas, a relação entre o teor de umidade ótimo e o teor de brita 1 é um polinômio do tipo parábola cúbica, ou polinômio de $3^{\circ}$ (terceiro) grau.

Figura 10 - Variação do teor de umidade ótimo versus teor de brita 1



Fonte: Acervo dos autores (2021)

3.1.1 Importantes variáveis físicas intervenientes no comportamento do teor de umidade ótimo das misturas

De acordo com Azevedo e Marques (2006), a porosidade, $\mathrm{n}$, das rochas metamórficas sãs ou intactas raramente ultrapassa 0 valor de $2 \%$. Sabe-se que a brita 1 é uma rocha metamórfica do tipo gnaisse. Assim, considerando-se a relação existente entre os índices físicos das rochas, pode-se admitir um valor máximo da porosidade da brita 1 como sendo $\mathrm{n}=0,02$. Nessas condições, sendo a densidade da brita 1 igual a $\mathrm{Gs}=2,663$, o seu teor de umidade saturado estimado será, aproximadamente, da ordem de $W_{\text {ot }}=0,77 \%$. Desse modo, fica claro que a brita 1 utilizada neste trabalho é praticamente estável em relação à água, quando misturada com o rejeito de manganês. Destacase, com base nas relações existentes entre os índices físicos do solo, que a porosidade do rejeito de manganês é, aproximadamente, $\mathrm{n}=$ 0,48 , e que o seu teor de umidade ótimo saturado calculado é igual a $28,12 \%$. Isso deixa claro que a afinidade do rejeito de manganês pela água é muito maior do que a apresentada pela brita 1 .

3.1.2 Influência da adição de brita 1 no teor de umidade ótimo das misturas

O fato de o teor de umidade ótimo da brita 1 ser praticamente estável em relação à água quando ela se encontra misturada com o rejeito de manganês e o fato de a porosidade do rejeito de manganês ser cerca de 24 vezes maior do que a porosidade da brita 1 tornam evidente que as quedas dos valores do teor de umidade ótimo das misturas são causadas, principalmente, pelo aumento da massa de brita 1 nessas misturas. Como os valores de outras variáveis, tais como: a 
temperatura no laboratório no momento da mistura, a umidade na superfície da bandeja onde se realiza a mistura etc. sofrem muito pouca alteração, elas têm baixíssima influência para esse tipo análise. Assim sendo, quando se adiciona maior massa de material estável, em relação à água, na mistura rejeito de manganêsbrita 1 de gnaisse, provoca-se, consequentemente, a diminuição da massa do rejeito de manganês, que é o material com maior afinidade pela água. Portanto, quando se retira da mistura o material com maior afinidade pela água fisicamente, ocorre uma diminuição do teor de umidade ótimo da mistura, que é tanto menor quanto maior for a adição do material estável em relação à água, como pode ser observado na figura 10 acima.

\subsection{Comportamento da massa específica seca máxima das misturas}

A figura 11 destaca a variação da massa específica seca máxima das misturas de rejeito de manganês-brita 1, para os teores de brita 1 , em massa, de $0 \%, 30 \%, 50 \%$ e $75 \%$, os quais foram obtidos nos ensaios laboratoriais de compactação de Proctor na energia intermediária. Pode-se verificar na figura 11 que, a partir do teor de brita de $30 \%$, à medida que se eleva o teor de brita (TB), tem-se que a massa específica seca máxima aumenta de forma quase linear. Observase também que a massa específica seca máxima alcança seu valor mais elevado, de $2,078 \mathrm{~g} / \mathrm{cm}^{3}$, para $75 \%$ de teor de brita 1 , em massa. Constatase ainda que, para as misturas rejeito de manganês-brita 1 , a relação entre massa específica seca máxima da mistura versus o teor de brita 1 , em massa, é uma parábola do $2^{\circ}$ grau, cujo modelo é apresentado na figura 11. Nota-se que $\circ \mathrm{R}^{2}$ do modelo estatístico obtido para a regressão não linear é igual a 0,9954, ou seja, um valor excelente, o que atesta a alta eficiência desse modelo em prever o valor da massa específica seca máxima para esse tipo mistura.

3.2.1 Importantes variáveis físicas intervenientes no comportamento da massa específica seca máxima das misturas

A porosidade considerada para a brita 1 , rocha metamórfica tipo gnaisse, foi da ordem de $n$ $=0,02$; assim, levando-se em conta o vínculo matemático existente entre os índices físicos das rochas, tem-se que o valor máximo do índice de vazios para brita 1 é estimado como sendo $e=$ 0,02. Assim, considerando-se uma relação existente entre a massa específica seca máxima $\left(\rho_{d}\right)$ e índice de vazios (e), tem-se que massa específica seca máxima da brita 1 calculada é, aproximadamente, $\rho_{d}=2,610 \mathrm{~g} / \mathrm{cm}^{3}$.

Quanto à massa específica seca máxima do rejeito de manganês, com base na figura 6 mostrada anteriormente, pode-se observar que 0 rejeito de manganês sem misturas e compactado na energia intermediária de Proctor alcançou uma massa específica seca máxima igual a 1,720 $\mathrm{g} / \mathrm{cm}^{3}$, ou seja, um valor bem abaixo do que o considerado para brita 1 .

3.2.2 A influência da adição de brita 1 na massa específica seca máxima das misturas

A massa específica seca máxima da brita 1 utilizada nas misturas nesta pesquisa é estimada como sendo cerca de 1,52 vezes mais elevada do que a massa específica seca máxima do rejeito de manganês sem misturas e compactado na energia intermediaria de Proctor. Levando em conta esse dado, pode-se observar (cf. Figura 11) que ocorre claramente uma elevação do valor da massa específica seca máxima da mistura à medida que se aumenta o teor de brita 1 , em massa, nas misturas do rejeito de manganês-brita 1, compactadas na energia intermediária de Proctor.

\subsection{Comportamento do CBR (California Bearing Ratio) das misturas}

A figura 12 ilustra a variação do CBR das misturas do rejeito de manganês-brita 1 para os teores de brita 1, em massa, de $0 \%, 30 \%, 50 \%$ e $75 \%$. Esses valores da variação foram obtidos nos ensaios CBR para compactação de Proctor na energia intermediária. Destaca-se que os ensaios de CBR foram realizados com base na norma NBR $n^{\circ} 9895 / 1987$ (ABNT, 1987) no Laboratório da EMURC em Vitória da Conquista BA. Pode-se observar na figura 12 que a partir do teor de brita de $30 \%$ o CBR da mistura aumenta de forma quase linear até o teor de brita de $50 \%$, mas a partir desse teor de brita, o gráfico mostra uma curva convexa e reduções nos valores de CBR. 
Figura 11 - Modelo e o gráfico de variação da massa específica seca máxima versus teor de brita 1, em massa, para mistura rejeito de manganês - brita

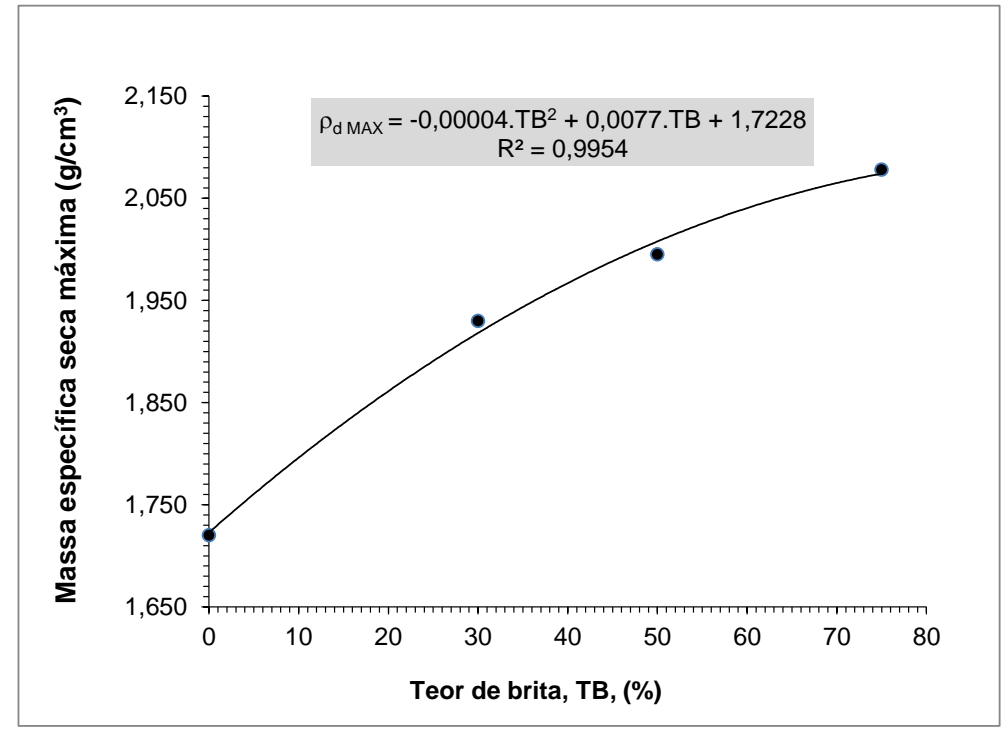

Fonte: Acervo dos autores (2021).

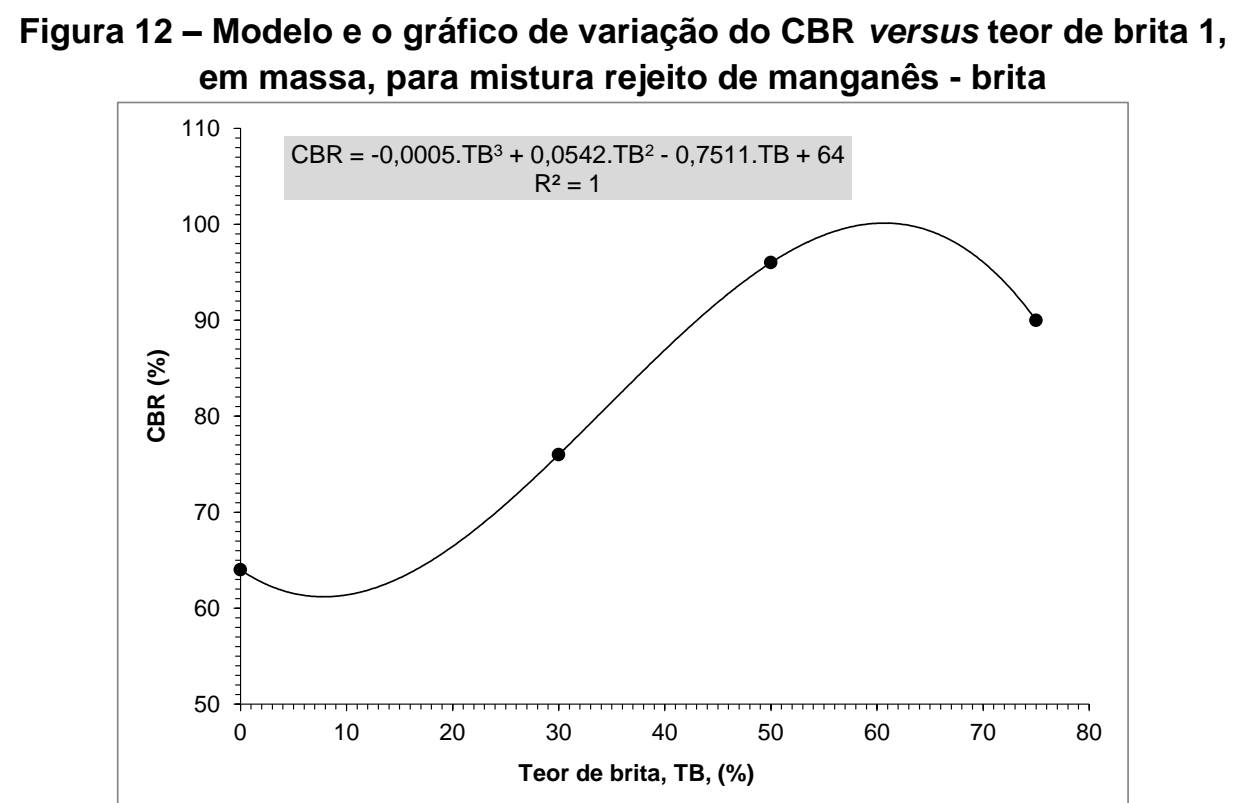

Fonte: Acervo dos autores (2021).

Para as misturas do rejeito de manganêsbrita 1 , a relação entre o CBR da mistura versus 0 teor de brita 1, em massa, é uma parábola cúbica ou do $3^{\circ}$ grau, cujo modelo também é mostrado na figura 12. Nota-se que $\circ \mathrm{R}^{2}$ do modelo estatístico do tipo regressão não linear apresentou um valor igual a 1 , ou seja, um valor excelente, o que atesta a alta qualidade desse modelo em realizar previsões para o valor do CBR da mistura em relação aos teores de brita 1 .
Cabe destacar que, caso na construção do modelo fosse utilizado um número maior de pontos, possivelmente, o valor do $\mathrm{R}^{2}$ diminuiria, mas somente um pouco, pois o fato de o valor de $\mathrm{R}^{2}$ do modelo ser 1 , já com 4 (quatro) pontos, é um forte indicativo da tendência cúbica e da alta qualidade desse modelo. Vale ainda informar que o erro médio relativo (EMR) foi medido, considerados todos os quatro pontos previstos com o modelo do CBR para a mistura estudada. 
Tal erro foi EMR $=4,37 \%$, ou seja, um erro muito baixo, o que qualifica ainda mais o modelo utilizado.

Em termos teóricos, considerando-se a equação do modelo apresentada na figura 12 , pode-se afirmar que com a utilização da mistura rejeito de manganês-brita 1, as exigências do DNIT (2006) quanto ao CBR para base de pavimentos podem ser atendidas satisfatoriamente a partir de um teor de brita 1 de $39,5 \%$, em massa, na mistura. Para esse teor, o valor de CBR previsto é igual a $88 \%$, ou seja, um valor um pouco acima do CBR de $80 \%$ exigido pela norma do referido órgão para construção de base de pavimentos rodoviários.

\subsubsection{Variáveis físicas intervenientes no} comportamento CBR

Em um ensaio CBR, tem-se que os principais elementos físicos envolvidos na mensuração do seu valor no material ensaiado é a tensão aplicada pelo cilindro da prensa desse equipamento de teste e a deformação apresentada pelo material compactado e inundado por 4 (quatro) dias. Em misturas de solo - brita 1, além das variáveis energia de compactação e umidade do material ensaiado, também influenciam no valor do CBR da mistura tanto a sua distribuição granulométrica como o módulo de elasticidade de cada um dos materiais misturados. Isso acontece porque a adição de um material com um elevado módulo de elasticidade, como a brita 1 , no rejeito de manganês, que é um solo, contribui diretamente para elevar a rigidez da mistura rejeito de manganês-brita $1 \mathrm{e}$, consequentemente, esta passa a ser mais rígida resultando em um material que sofrerá menores deformações, mesmo quando submetido a grandes pressões de cargas como as de veículos pesados, as de ensaios e as provenientes de outros eventos.

Diante disso, neste subitem é feito um breve comentário, com embasamentos teóricos e experimentais, acerca da influência que tanto a granulometria das misturas como também os módulos de elasticidade individuais dos materiais misturados exercem nos valores do CBR das misturas do rejeito de manganês-brita 1 .

Sabe-se que a brita 1 utilizada neste trabalho teve sua origem no esmagamento de rocha do tipo gnaisse. A propósito, para se ter uma noção do valor do módulo de elasticidade de rocha gnaisse, Bauer (1992) destaca que o valor típico do módulo de elasticidade das rochas desse tipo está na faixa de 460.000 e $660.000 \mathrm{kgf} / \mathrm{cm}^{2}$. Já para solos, alguns dos valores típicos de módulo de elasticidade são destacados por Bueno e Vilar (2002). De acordo com esses autores, para solos do tipo areia siltosa, os valores típicos do módulo de elasticidade variam de 50 a $200 \mathrm{kgf} / \mathrm{cm}^{2}$.

Conforme já foi descrito, o rejeito de manganês utilizado neste trabalho é classificado como sendo um solo do tipo areia siltosa (SM para a classificação USCS). Convém ressaltar que, embora a medida do módulo de elasticidade do rejeito de manganês utilizado neste trabalho não tenha sido feita de modo direto, ou seja, por meio do ensaio de compressão axial não confinado, é possível estimar o valor de tal módulo, de modo aproximado, por meio do ensaio CBR através de correlações.

Sabe-se que alguns solos apresentam distribuições granulométricas favoráveis à ocorrência de um bom travamento entre as partículas, ou seja, distribuições granulométricas em que os espaços deixados pelas partículas maiores são ocupados de uma forma melhor pelas partículas menores. Esses solos denominados de bem graduados, quando compactados, apresentam, entre outras melhorias físicas, um aumento significativo não só da sua resistência como também do seu módulo de elasticidade. Consequentemente, tratando-se de corpos de prova padronizados, em ensaios CBR, compressão axial não confinada etc., geralmente ocorre que, quando o valor do módulo de elasticidade do solo aumenta, tem-se que tanto o valor de rigidez como o valor do CBR medidos também aumentam.

Além disso, a diferença de rigidez dos dois materiais que formam as misturas de rejeito de manganês-brita 1 é considerável, pois a brita1 de rocha tipo gnaisse tem um valor de módulo de elasticidade muito elevado em relação ao módulo de elasticidade do rejeito de manganês (ou solo), mesmo quando o rejeito de manganês está compactado na energia intermediária de Proctor.

Sabe-se que o CBR e o módulo de elasticidade $(E)$ são variáveis correlatas, pois tanto o CBR como o módulo de elasticidade de um solo se unem em temos matemáticos com base no índice de penetração do ensaio Dynamic Cone Penetration, ou simplesmente DCP. 
Utilizando-se duas equações, eq. (1) e eq. (2), foi possível calcular, de modo aproximado, o módulo de elasticidade do solo a partir do CBR, considerando-se a variável DPC. Vale ressaltar ainda que o ensaio Dynamic Cone Penetration é realizado por meio da penetração dinâmica no solo de um cone de $20 \mathrm{~mm}$ de diâmetro e chanfrado em 60 graus.

Para se obter a eq. (1), que estima O DCP em função do CBR, utilizada neste trabalho, foi necessário realizar uma inversão na correlação de Trichês e Cardoso (1998 apud CARVALHO, 2005), a qual apresentava uma boa precisão com $\mathrm{R}^{2}=0,90$.

Já a eq. (2) apresentou $R^{2}=0,996$ para valores de DCP variando de 1 a $75 \mathrm{~mm} / \mathrm{golpes}$. Tal equação foi elaborada considerando-se duas correlações: uma com um $\mathrm{R}^{2}=0,995$, apresentada no trabalho de Sachet (2007) para avaliar o módulo de elasticidade; a outra foi a referida correlação utilizada na elaboração da eq. (1).

$D C P=10^{(2,71-\log (C B R)) / 1,25}$

sendo:

$E=2208,4 .(D C P)^{-1,377}$

em que:

$\mathrm{DCP}=$ índice de penetração Dynamic Cone Penetration (mm/golpes);

$\mathrm{CBR}=$ California Bearing Ratio (\%);

$\mathrm{E}=$ módulo de elasticidade do solo (MPa).

3.3.2 Influências da distribuição granulométrica e do módulo de elasticidade da brita 1 no comportamento CBR

Segundo Pinto (2006), os pedregulhos e as areias são considerados solos bem graduados quando os valores dos seus coeficientes de não uniformidade (CNU) são superiores a 4 e 6 , respectivamente. Além disso, em um material bem graduado, é necessário também que 0 coeficiente de curvatura (CC) da curva granulométrica esteja entre 1 e 3.

Muito útil para discorrer sobre o comportamento das misturas quanto ao CBR é a figura 13 , que mostra as curvas de distribuição granulométricas das misturas de rejeito de manganês-brita 1 e a curva granulométrica do rejeito de manganês (RJM) sem qualquer mistura, e que foram construídas matematicamente via programa Excel. Também é importante a tabela 2 abaixo, em que se destaca o valor do CNU e CC de cada mistura e do rejeito de manganês sem misturas.

Quanto à granulometria das misturas, podese afirmar que a melhor mistura foi a 1 , pois nesta o CC está dentro do exigido e seu CNU é superior a 6 . Em termos granulométricos, a mistura 2 é melhor do que a mistura 3 , pois na mistura 20 CNU está dentro da exigência e o CC está mais próximo do intervalo exigido, uma vez que se multiplicando o $\mathrm{CC}=0,04$ por 25 da mistura 2 obtém-se um valor que está dentro do intervalo exigido. Em relação à mistura 3 , o valor do $\mathrm{CNU}$ está dentro do exigido, contudo o valor do $\mathrm{CC}=$ 163,64 precisa ser divido por, aproximadamente, 55 para estar na faixa de material bem graduado de acordo com Pinto (2006). Com base no valor de CC encontrado, a mistura 3 é cerca de mais de 2,2 vezes pior, ou mais distante do intervalo ideal para esse coeficiente, do que a mistura 2. Assim sendo, a mistura 2 é melhor do que a 3.

Levando-se em consideração a tabela 2 , o rejeito de manganês sem misturas supera em qualidade, em termos granulométricos (CNU e $\mathrm{CC}$ ), as misturas 2 e 3 . $O$ rejeito de manganês sem misturas é um solo que se enquadra nas exigências granulométricas para material bem graduado. Entretanto, o rejeito de manganês sem misturas apresentou baixo valor de CBR $=64 \%$, ao passo que as misturas 2 e 3 apresentaram esses valores elevados: $\mathrm{CBR}=96 \%$ e $\mathrm{CBR}=90$ $\%$, respectivamente.

Diante do exposto, com base na distribuição granulométrica, não é possível apresentar um argumento teórico satisfatório para explicar os elevados CBRs das misturas 2 e 3 . Entende-se então que o motivo para os elevados CBRs das misturas 2 e 3 podem ser explicados com base na elevação do módulo de elasticidade dessas misturas em decorrência da adição de maiores teores da brita 1, pois este material possui 0 módulo de elasticidade muito mais elevado do que o módulo de elasticidade do rejeito de manganês sem misturas, mesmo quando compactado. Portanto, conclui-se que o fator causador da elevação total nos valores do módulo de elasticidade das misturas 2 e 3 , resultando no aumento dos valores da rigidez axial e, consequentemente, dos valores de CBR, é 
justamente a adição da brita 1 na composição das misturas.

A tabela 3 mostra os valores do módulo de elasticidade e da rigidez axial obtidos, teoricamente e de modo aproximado, tanto para as misturas do rejeito de manganês-brita 1 como também para 0 rejeito de manganês sem misturas. Para que fosse possível realizar o cálculo da rigidez axial, considerou-se um corpo de prova padrão com $11,50 \mathrm{~cm}$ de diâmetro e 23 $\mathrm{cm}$ de altura, para uma compressão não confinada. Tal corpo de prova padronizado apresenta uma rigidez axial igual a, aproximadamente, 103,87.E $\quad\left(M P a . \mathrm{cm}^{2}\right)$ ou 0,010387.E (MPa.m²) - E corresponde ao módulo de elasticidade. Contudo, para o cálculo da rigidez axial, o valor do módulo de elasticidade de cada mistura foi obtido de forma indireta a partir das eq. (1) e eq. (2), considerando-se os valores do CBRs, que também são apresentados na tabela 3.
Como mostra a tabela 3 , o módulo de elasticidade da mistura 2 foi maior do que o da mistura 3 , ainda que esta contivesse mais brita 1 do que a mistura 2. Assim sendo, consequentemente, a rigidez da mistura 2 também é mais elevada, o que contribui para haver deformações menores quando essa da mistura estiver submetida a carregamentos. Isso também resulta em aumento no valor do CBR da mistura 2. Diante das informações, fica claro que o fator prejudicial é a distribuição granulométrica da mistura 3 , isto é, o fator que causou a diminuição do valor do módulo de elasticidade dessa mistura e, consequentemente, também a diminuição do valor da rigidez axial do corpo de prova. Mesmo com maior teor de brita 1 , a mistura 3 apresentou menores valores do CBR, do módulo de elasticidade e da rigidez axial do que aqueles apresentados pela mistura 2 (Tabela 3).

\section{Figura 13 - Curvas de distribuição granulométricas das misturas do rejeito de manganês- brita 1, e a curva granulométrica do rejeito de manganês (RJM)}

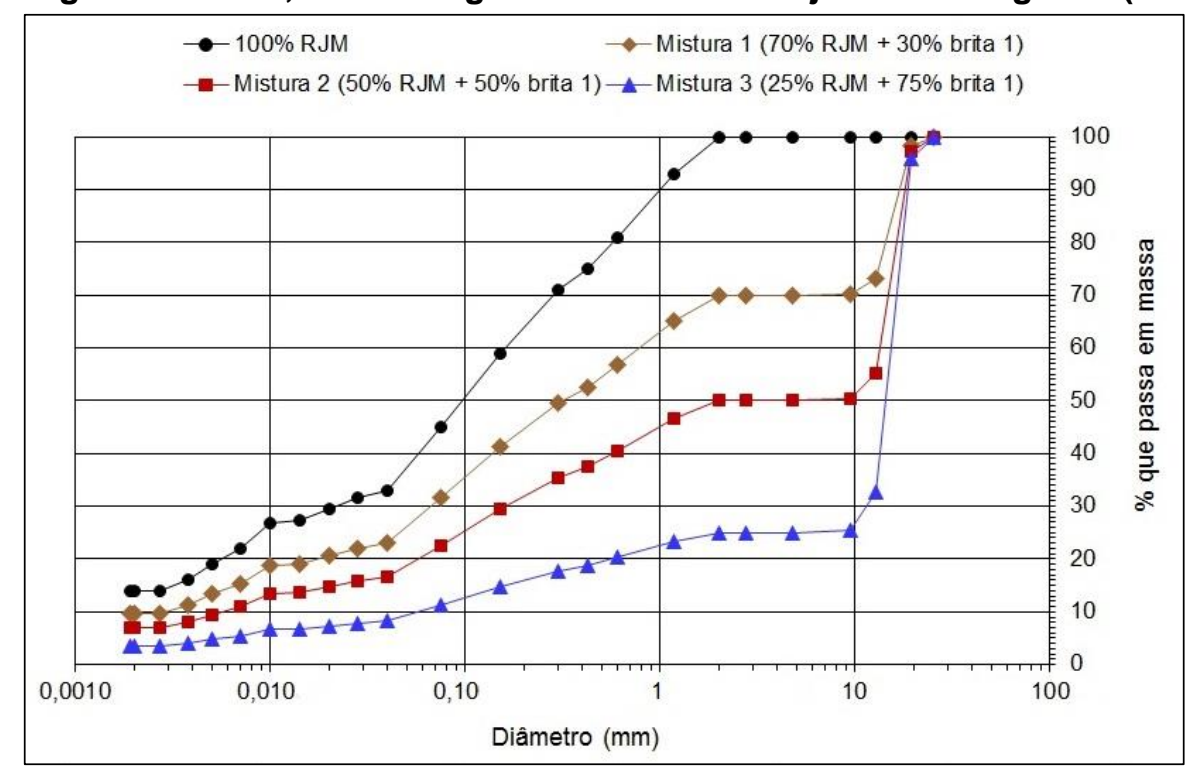

Fonte: Acervo dos autores (2021).

Tabela 2 - Valores do CNU e CC de cada mistura e do rejeito de manganês puro

\begin{tabular}{|c|c|c|c|}
\hline Materrial & $\%$ brita 1 (em massa) & CNU & CC \\
\hline Rejeito & 0 & Infinito & 1,07 \\
\hline Mistura 1 & $30 \%$ & 250 & 1,09 \\
\hline Mistura 2 & $50 \%$ & 2333 & 0,04 \\
\hline Mistura 3 & $75 \%$ & 291 & 163,64 \\
\hline
\end{tabular}


Tabela 3 - Valor do módulo do CBR, do módulo de elasticidade e da rigidez axial para cada mistura e para o rejeito de manganês sem misturas

\begin{tabular}{|c|c|c|c|c|}
\hline Mistura & $\begin{array}{c}\text { Teor de brita 1 } \\
\text { (em massa) }\end{array}$ & CBR (\%) & E (MPa) & $\begin{array}{c}\text { Rigidez axial } \\
\left(\text { MPa.m }^{2}\right)\end{array}$ \\
\hline Rejeito & $0 \%$ & 64 & 223,1 & 2,317 \\
\hline Mistura 1 & $30 \%$ & 76 & 269,6 & 2,800 \\
\hline Mistura 2 & $50 \%$ & 96 & 348,7 & 3,622 \\
\hline Mistura 3 & $75 \%$ & 90 & 324,7 & 3,373 \\
\hline
\end{tabular}

Fonte: Acervo dos autores (2021).

\subsection{Comportamento da expansão CBR das misturas}

A figura 14 destaca a variação da expansão CBR das misturas do rejeito de manganês-brita 1 para os teores de brita 1 de $0 \%, 30 \%, 50 \%$ e $75 \%$, em massa, nos ensaios e para compactação de Proctor na energia intermediária. Nessa figura, pode-se verificar que para as misturas rejeito de manganês-brita 1 , a relação entre a expansão CBR versus o teor de brita 1 resultou em um modelo do tipo regressão não linear parábola do $2^{\circ}$ grau, com uma curva decrescente com o aumento do teor de brita, e apresentou o valor $R^{2}$ igual a 0,7517 , ou seja, um valor mediano, contudo satisfatório para realizações das previsões quanto à expansão CBR nesse tipo de mistura. Considerando-se um teor de brita 1 de 39,5\%, em massa, na mistura, tem-se que a previsão para a expansão CBR com o modelo em questão foi igual a $0,05 \%$, tal valor atende de modo mais do que satisfatório as exigências das especificações do DNIT (2006) para construção de base de pavimentos rodoviários.

3.4.1 Aspectos do rejeito de manganês e da brita 1 relacionados à expansão CBR

A caulinita é o argilo-mineral presente no rejeito de manganês, como se pode verificar no difratograma mostrado anteriormente na figura 5 . Além disso, sabe-se que o argilo-mineral do tipo caulinita é muito pouco expansivo, pois a sua estrutura mineral é bastante resistente à entrada da água. Com base na curva granulométrica da figura 3, percebe-se que o teor de argila presente no rejeito de manganês é da ordem $20 \%$. Entretanto, é preciso esclarecer que nem toda fração argila (partículas com diâmetro menor que $0,005 \mathrm{~mm}$ ) do rejeito de manganês é tão somente do tipo caulinita, pois podem existir argilas de outras classes de minerais no rejeito que sejam estáveis em relação à água. Diante do exposto, entende-se o porquê de o rejeito de manganês sem adições ter apresentado uma baixíssima expansão CBR, que foi da ordem de $0,1 \%$.

Acrescenta-se ainda, com base na DNER EM 037 (DNER, 1997a), que as britas devem ser oriundas de rochas comprovadamente inertes, e tais britas quando submetidas ao umedecimento devem apresentar uma estrutura pétrea, que não cause expansões deletérias onde são utilizadas como agregado graúdo.

3.4.2 Caráter inerte da brita 1 e sua Influência na diminuição da expansão

Considerando-se apenas as medidas diretas da expansão CBR feitas no laboratório, que são os pontos da figura 14, inicialmente percebe-se que a brita 1 utilizada neste estudo é um material praticamente inerte em relação à expansão CBR causada pela água, pois a mistura rejeito de manganês-brita 1 apresenta um valor de expansão CBR constante e igual a $0,1 \%$ para teores de brita 1 no intervalo de $0 \%$ até de $30 \%$ de brita 1, em massa.

Além do mais, com base nos dados expostos na figura 14, percebe-se que há uma queda de expansão CBR, quando o teor de brita 1 passa de $30 \%$ para $50 \%$. Seguramente, então, encontra-se nesse intervalo o valor exato do teor de brita 1 , em massa, que é capaz de anular totalmente a expansão CBR para uma mistura de rejeito de manganês-brita 1. Isso fortalece, ainda mais, o caráter inerte da brita 1 em relação à água e à expansão CBR. Finalmente, para confirmar mais uma vez o caráter inerte da brita 1 em relação à água, pode-se verificar, na figura 14 , que não ocorre qualquer queda no valor da expansão CBR das misturas, mesmo para teores de brita 1 
maiores do que $50 \%$, em massa, uma vez que o valor da expansão permanece constante igual
$0,00 \%$ tanto para o teor de $50 \%$ como para o teor $75 \%$ de brita 1 .

\section{Figura 14 - Modelo e o gráfico de variação da expansão CBR versus teor de brita 1, em massa, para mistura rejeito de manganês-brita}

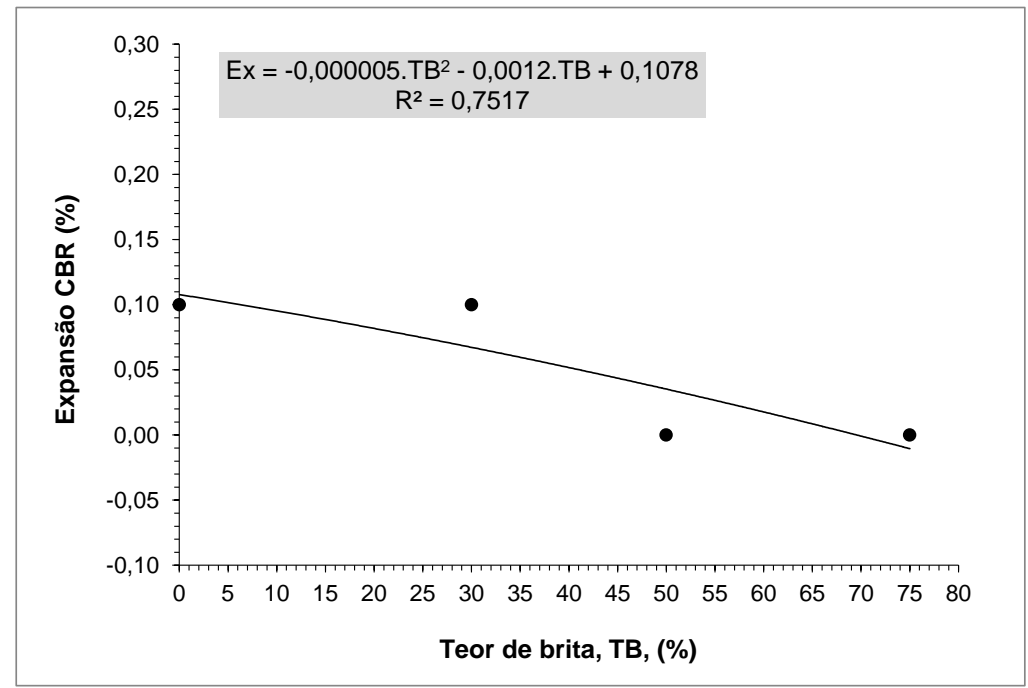

Fonte: Acervo dos autores (2021).

\section{CONCLUSÕES}

Considerando-se 0 exposto neste trabalho quanto à utilização da brita 1 de rocha tipo gnaisse em teores de $0 \%, 30 \%, 50 \%$ e $75 \%$, em massa, em uma mistura de rejeito de manganêsbrita 1 , as conclusões são as que se seguem:

i) A brita 1 apresentou-se como sendo um material útil para estabilizar 0 rejeito de mineração de manganês para finalidades rodoviárias de tráfego pesado.

ii) Com a utilização de um modelo estatístico de regressão não linear de elevada qualidade $\left(R^{2}=1\right.$ e $E M R=4,37 \%$ ), pode-se afirmar que a exigência do DNIT para a base de pavimentos rodoviários para tráfego pesado, que é de $C B R \geq 80 \%$, foi nitidamente satisfeita. Por meio da utilização desse modelo de regressão não linear para um teor de brita 1 de $39,5 \%$, em massa, na mistura rejeito de manganês-brita 1 , o valor de CBR previsto foi igual a $88 \%$, que ultrapassa o exigido pela norma vigente.

iii) Apesar de sua qualidade mediana $\left(R^{2}=0,75\right)$, o modelo estatístico de regressão não linear do tipo parábola do $2^{\circ}$ grau mostrou-se totalmente seguro para alcançar os objetivos para os quais foi concebido. Com sua utilização neste trabalho, obteve-se um resultado que atende, além do que seria suficiente, à exigência do DNIT para base de pavimentos rodoviários para tráfego pesado, que é de expansão $C B R \leq 0,50 \%$, pois através da previsão desse modelo de regressão não linear, para um teor de brita 1 de 39,5\%, em massa, na mistura rejeito de manganês-brita 1 , chegou-se a um valor de expansão CBR igual $0,05 \%$.

iv) É possível obter o módulo de elasticidade do solo, de modo aproximado, a partir de correlações existentes entre o DCP (Dynamic Cone Penetration) e o CBR do solo.

v) Finalmente, pode-se concluir que o trabalho alcançou seus objetivos iniciais, pois com a mistura rejeito de manganês-brita 1 torna-se real uma nova possibilidade de obter dois benefícios: primeiro, combater um problema de impacto ambiental causado pelo descarte do rejeito de manganês no meio ambiente, o que pode poluir rios e lagos; e segundo, a mistura rejeito de manganês-brita 1 também produz, em termos teóricos baseados em dados obtidos de modelos estatísticos de CBR e expansão, um excelente material para construção de base de pavimentos rodoviários, quando estabilizado com um teor de brita 1 de $39,5 \%$, em massa, na mistura. 


\section{AGRADECIMENTOS}

Ao técnico José Augusto Lopes da Rocha do Instituto de Física de São Carlos da Universidade de São Paulo (IFSC - USP), aos técnicos do Laboratório de Geotecnia da Universidade Federal de Viçosa - MG (UFV), ao técnico Francisco do Laboratório de Geotecnia da EMURC, em Vitória da Conquista - BA.

\section{REFERÊNCIAS}

ASSOCIAÇÃO BRASILEIRA DE NORMAS TÉCNICAS - ABNT. NBR 6457: Solo - amostras de solo Preparação para ensaios de compactação e de caracterização. Rio de Janeiro, 1986a. 9 p.

NBR 9604: Abertura de poço e trincheira de inspeção em solo, com retirada de amostras deformadas e indeformadas: procedimento. Rio de Janeiro, 1986b. 9 p.

NBR 9895: Solo - índice de suporte Califórnia. Rio de Janeiro, 1987. $14 \mathrm{p}$.

AZEVEDO, I. C. D.; MARQUES, E. A. G. Introdução à mecânica das rochas. Viçosa - MG: UFV, 2006. 360 p.

BALBO, J. T. Pavimentação asfáltica. 1. ed. São Paulo: Oficina de Textos, 2007. 558 p.

BAUER, L. A. F. Materiais de construção. 4. ed. Rio de Janeiro - RJ: LTC (Livros Técnicos Científicos), 1992. vol. 1. 435 p.

BERNUCCI, L. B. et al. Pavimentação asfáltica Formação básica para engenheiros. Rio de Janeiro: ABEDA (Associação Brasileira das Empresas Distribuidoras de Asfaltos), 2008. 501p.

BEZERRA NETO, R. S. Análise comparativa de pavimentos dimensionados através dos métodos empírico do DNER e mecanístico e proposta de um catálogo simplificado de pavimentos para a região de Campo Grande (MS). 2004. 169 p. Dissertação (Mestrado em Engenharia de Transportes) - Escola de Engenharia de São Carlos, Universidade de São Paulo, São Carlos - SP, 2004. Disponível em:

$<$ https://www.teses.usp.br/teses/disponiveis/18/18137/t de-03052004-153504/publico/dissertacao_rogerio.pdf>. Acesso em: 11 nov. 2020.

BUENO, B. S.; VILAR, O. M. Mecânica dos solos. São Carlos - SP: Escola de Engenharia de São Carlos USP, 2002. vol. 2. 219 p.
CARVALHO, R. G. Correlações entre os ensaios DCP e CBR para solos saprolíticos de textura fina. 2005. 141 p. Dissertação (Mestrado em Engenharia de Infraestrutura Aeronáutica) - Instituto Tecnológico de Aeronáutica, São José dos Campos - SP, 2005.

Disponível em:

$<$ https://bdtd.ibict.br/vufind/Record/ITA_4a66589440a8 9b904339613e5b2fbbed>. Acesso em: 28 nov. 2020.

CASTRO, C. G. Estudo do aproveitamento de rejeitos do beneficiamento do manganês pela indústria cerâmica. 2011. 108 p. Dissertação (Mestrado em Engenharia de Materiais) - Universidade Federal de Ouro Preto, Ouro Preto, 2011.

\section{DEPARTAMENTO NACIONAL DE ESTRADAS E} RODAGEM - DNER. DNER-ME 049: Solos -

Determinação do índice de suporte Califórnia. Rio de Janeiro, 1994. 14 p.

. DNER-ME 037: Agregado graúdo para concreto de cimento. Rio de Janeiro, 1997a. 6 p.

Glossário de termos técnicos rodoviários. Rio de Janeiro, 1997b. 296 p.

. DNER-ME 081: Determinação da absorção e da densidade de agregado graúdo. Rio de Janeiro, 1998. 6 p.

DEPARTAMENTO NACIONAL DE INFRAESTRUTURA DE TRANSPORTES - DNIT. Manual de pavimentação. 3. ed. Rio de Janeiro, 2006. 274 p.

FRANÇA, F. C. Estabilização química de solos para fins rodoviários: Estudo de caso com o produto “RBI GRADE 81". 2003. 104 p. Dissertação (Mestrado em Engenharia Civil) - Universidade Federal de Viçosa, Viçosa, 2003.

\section{INSTITUTO BRASILEIRO DE GEOGRAFIA E} ESTATÍSTICA - IBGE. Base de dados. População estimada em 2018 para o município de cidade de Licínio de Almeida - BA. Rio de Janeiro, 2019. Disponível em: $<$ https://cidades.ibge.gov.br/brasil/ba/licinio-dealmeida/panorama>. Acesso em: 14 maio 2019.

MEDEIROS, M. de A. Manganês - aplicações e envolvimento com a saúde. QuiProcura. 2015. Disponível em: $<$ https://quiprocura.net/w/2015/11/16/manganesaplicacoes-e-envolvimento-com-a-saude/>. Acesso em: 15 maio 2019.

MENDONÇA, A. A.; BUENO, B. S.; FONTES, M. P. F. Caracterização tecnológica de misturas solo-cal: estudo de caso dirigido a dois solos de Viçosa - MG. In: 
CONGRESSO BRASILEIRO DE MECÂNICA DOS

SOLOS E ENGENHARIA GEOTÉCNICA, 11., 1998,

Brasília. Anais [...]. Brasília: ABMS (Associação

Brasileira de Mecânica dos Solos), 1998. v. 2, p. 1175-

1182.

NOGAMI, J. S.; VILLIBOR, D. F. Pavimentação de baixo custo com solos lateríticos. São Paulo - SP: Villibor, 1995. 213 p.

OLIVEIRA Jr., J. M. R.; ARAÚJO, C. B. C.; AYRES, T. M. C. Estudo comparativo entre as misturas solo-seixo e solo-brita para fins de pavimentação, Revista

Tecnologia, Fortaleza, v. 39, n. 1, p. 1-18, jun. 2018.

Disponível em:

<https://periodicos.unifor.br/tec/article/view/7905/5716>. Acesso em: 13 de nov. 2020.

PINTO, C. S. Curso básico de mecânica dos solos. 3. ed. São Paulo - SP: Oficina de Textos. 2006. 335 p.

PINTO, S.; PINTO, I. E. Pavimentação asfáltica. Rio de Janeiro - RJ: LTC (Livros Técnicos e Científicos), 2015. 269 p.

SACHET, T. Controle tecnológico de obras rodoviárias envolvendo a reciclagem in situ de bases granulares de pavimentos asfálticos. 2007. 172 p. Dissertação (Mestrado em Engenharia) Universidade de Passo Fundo, Passo Fundo - RS, 2007. Disponível em:

<http://tede.upf.br/jspui/bitstream/tede/223/1/2007TaiSa chet.pdf>. Acesso em: 12 dez. 2020.

SACHET, T. et al. Uso de fresado asfáltico em concreto compactado com rolo para pavimentação. In: REUNIÃO DE PAVIMENTAÇÃO URBANA, 19., 2009, Belo Horizonte - MG. Anais [...]. Rio de Janeiro: ABP (Associação Brasileira de Pavimentação), 2009. CD, 12 p.

XEREZ NETO, J. Pavimentos de concreto para tráfego de máquinas ultrapassadas. São Paulo - SP: Pini, 2013. $154 \mathrm{p}$. 